\title{
IX. Bibliographische Hinweise auf Textsammlungen und DARSTELlungen zUR ARBEITERLITERATUR FÜr DEN UNTERRICHT
}

I. D. Arnold-Dielewicz/H. L. Arnold (Hg.), Arbeiterliteratur in der Bundesrepublik Deutschland, Stuttgart 1975.

$K$. Brübach/K. Hamann (Hg.), Menschen in der Welt der Arbeit, 2 Bde., Frankfurt/M., 1968/69 u. ö.

R. Dithmar, Literatur der Arbeitswelt, 2 Bde.: Schülerarbeitsbuch, Lehrerband, Stuttgart 1976 (Deutsch in der Sekundarstufe 1).

A. Folkers/U. Gronwald, Literatur der Arbeiterklasse - Produktions- und Rezeptionsbedingungen von Arbeiterliteratur und ihre Geschichte in der Weimarer Republik, im Dritten Reich, BRD und DDR, in: H.-G. Hölsken/W. W. Sauer/R. Schnell (Hg.), Sprache, Literatur und Kommunikation für das Fach Deutsch in der Sekundarstufe II, Stuttgart 1974 (Zur Praxis des Deutschunterrichts 2), S. 78-114.

J.-W. Goette (Hg.), Arbeiterliteratur. Texte zur Theorie und Praxis, Frankfurt/M./Berlin/München 1975.

$K$. Hildebrandt/K. Möbring, Texte aus der Arbeitswelt/K. Hildebrandt, Texte zur Lage der Arbeiter in der Bundesrepublik - Unterrichtspraktische Hinweise, in: H. Ide/Bremer Kollektiv (Hg.), Projekt Deutschunterricht 4: Sprache und Realität, Stuttgart 1973, S. 120-137/138-151 (dazu: Materialienteil).

G. Lange (Hg.), Im Getriebe, Frankfurt/M. 1968 u.ö.

-, Im Glasbetonbau, Frankfurt/M. 1971 u. ö.

H. Riebe, Arbeitswelt und Literatur, 2 Bde.: Textheft, Begleitheft, Dortmund 1973.

F. Vaßen, Arbeiterliteratur, in: E. Dingeldey/J. Vogt (Hg.), Kritische Stichwörter zum Deutschunterricht, München 1974 (UTB 299), S. 15-27.

Diskussion Deutsch, Heft 18 (Aug. 1974): Arbeiterliteratur.

$F$. Winterling, Darstellung der Technik in der Literatur, in: $H$. Sachse (Hg.), Technik und Gesellschaft, Bd. 1: Literaturführer, Pullach bei München 1974 (UTB 413), S. 168-205. 